\title{
Monitoring Level Fluctuations of the Lakes in the Yangtze River Basin from Radar Altimetry
}

\author{
Yonghai Chu ${ }^{1, *}$, Jiancheng $\mathrm{Li}^{1}$, Weiping Jiang ${ }^{1}$, Xiancai Zou ${ }^{1}$, Chunbo Fan ${ }^{1}$, Xinyu Xu${ }^{1}$, and Isaac Dadzie ${ }^{2}$ \\ ${ }^{1}$ School of Geodesy and Geomatics, Wuhan University, Wuhan, 430079, China \\ ${ }^{2}$ Faculty of Civil and Geomatic Engineering, Knust, Kumasi, Ghana
}

Received 15 November 2006, accepted 23 June 2007

\begin{abstract}
Water level variations in four natural lakes, Poyang, Dongting, Tai, and Chao, within the Yangtze River basin are studied using ENVISAT GDRs. The GDRs were edited using simple editing criteria and appropriate geophysical corrections applied. Altimeter-derived lake level variation time series were then generated and analyzed. The results of this study, which is the first of its kind in using data from ENVISAT missions over the Yangtze River basin in China, reveal that the water level changes in these four lakes directly reflect the water level of the Yangtze River and contribute to the floods and their associated disasters that usually occur in the middle and lower reaches of the Yangtze River.
\end{abstract}

Key words: Satellite altimetry, Inland lake, Lake level variation, Yangtze River basin

Citation: Chu, Y., J. Li, W. Jiang, X. Zou, C. Fan, X. Xu, and I. Dadzie, 2008: Monitoring level fluctuations of the lakes in the Yangtze River basin from radar altimetry. Terr. Atmos. Ocean. Sci., 19, 63-70, doi: 10.3319/TAO.2008.19.1-2.63(SA)

\section{INTRODUCTION}

Satellite altimeters, primarily designed to provide data for studying the oceanic domain, have been used to investigate oceanography (WOCE/NASA 1988; Chelton et al. 2001; Jiang 2001) and polar ice-sheet (Phillips 1999) since the 1970s. But prior to the advent of RA-2 altimeter, carried by ENVISAT (launched in March 2002), using radar altimeters to collect radar echoes from land was a rather demanding task since it implied design of a robust tracking algorithm for onboard real time processing to avoid losing tracking. Now, this has been successfully met by the RA-2 design thanks to an innovative tracking algorithm developed in ALS known as Model Free Tracker (MFT). The RA-2 altimeter now collects, on a global scale, radar echoes from ocean, land, and ice without interruption.

By using the new tracking algorithm and with the high spatial resolution of ENVISAT, RA-2 measurements can now be used to investigate inland lake or river level fluctuation when the surface area of the water body is large enough to reflect the signal to the altimeter. Research by Zhang et al. (2006) indicated that radar altimeter measurements over

\footnotetext{
* Corresponding author

E-mail: yh_chu@163.com
}

inland waters are reliable when the width of the water body is larger than $0.5 \mathrm{~km}$ and the performance of the altimeter is fine. Since the launching of Geosat, ERS1/2, and Topex/ Poseidon, higher accuracy lake observations were made available and many researchers including Ponchaut et al. (1998), Zhang (2002), and Chu et al. (2005) have used them to study lake level variations; Birkett (1995), Birkett et al. (1999), Mercier et al. (2002), and Hwang et al. (2005) have employed them to study the relationship between level fluctuations and climatic change while Jekeli et al. (2003) used them to investigate the relationship between level fluctuation and vertical datum. The Amazon basin is the main investigated place over which altimetry measurements are applied to rivers (Birkett 1998; Campos et al. 2001) while Morris and Gill (1994) report some work that has also been done over the Great Lakes.

This study is the first of its kind in using 3 years of data from ENVISAT missions over the Yangtze River basin in China, and it involves discussing the correlation between altimeter-derived water level fluctuations of Poyang, Dongting, Tai and Chao lakes and climatic changes within the basin with a view of providing data for flood prediction and control. 


\section{THE YANGTZE RIVER BASIN AND ITS LAKES}

The Yangtze River is the largest river in China and the third largest river in the world. It is located in a subtropical zone and is affected by the southeast and southwest monsoons. Convectional rains bring about heavy rainstorms and torrential rainfalls. Annual mean precipitation within the basin could amount to $1000 \mathrm{~mm}$. In the middle and lower reaches of the basin (see Fig. 1), there is a dendritic pattern of river distribution with many rivers crossing each other like a web. The basin is characterized by floods and disasters for the water levels of the rivers in the middle and lower reaches of the Yangtze are as low as $10 \mathrm{~m}$. Four of the severest floods causing the most devastating disasters in Chinese history took place in 1931, 1935, 1954, and 1998. Relief of the Yangtze River basin consists of undulating mountains and hills and plateaus covering about 85 percent of the total surface area but the terrain in the middle and lower reaches of the Yangtze is relatively flat, and hence most susceptible to flooding.

Distribution of lakes in China is, generally, uneven. The Yangtze River basin, having five of the largest fresh water lakes, is one of the densest places of lake distribution. Figure 1 shows the middle-lower reaches of the Yangtze River and its lakes. Besides the blue ocean, the permanent major river (Yangtze River) is plotted in thick blue pen, additional major rivers in thin blue pen, and the provincial boundary as a thin red line. Many oxbow and regular lakes, dispersed in the form of a butterfly, are connected to the Yangtze River on both sides of it. The degree of water intake and discharge by the lakes within the basin directly impact on the flood pattern within the basin. Siltation and reclamation of wetlands by farmers for cultivation result in reductions of lake volumes leading to smaller water intake volumes during the flood periods. Two of the lakes studied in this work, Tai and Chao, have floodgates to control the flow of water to and from the Yangtze River. The Poyang and Dongting lakes connect directly to the Yangtze River. Figure 2 shows the geographical locations of the 4 studied lakes and data distribution.

\section{DATA DESCRIPTION AND PROCESSING}

RA-2 is nadir-looking pulse limited radar functioning at the main nominal frequency of $13.575 \mathrm{GHz}$ (Ku band). The secondary channel at nominal frequency of $3.2 \mathrm{GHz}$ ( $\mathrm{S}$ band) is also operated to compute corrections to the measured range to compensate for the ionosphere delay. The RA-2 telemetry provides 18 range measurements per second, which corresponds to an along-track sampling interval of about $400 \mathrm{~m}$. Over the ocean it is common to average 20 of these measurements to give a sampling interval of 1.1 seconds or about $8 \mathrm{~km}$.

The RA-2 data products are based on one main geophysical data record (GDR) product. The general format of the ENVISAT product is exploited to add sub-structure inside the product to hold additional data such as the averaged waveforms (at $18 \mathrm{~Hz}$ ), the individual waveforms (at $1800 \mathrm{~Hz}$ ) and the microwave radiometer data set. Moreover, following a user requirement survey, these products were made global, independent of the sub-satellite terrain and of the

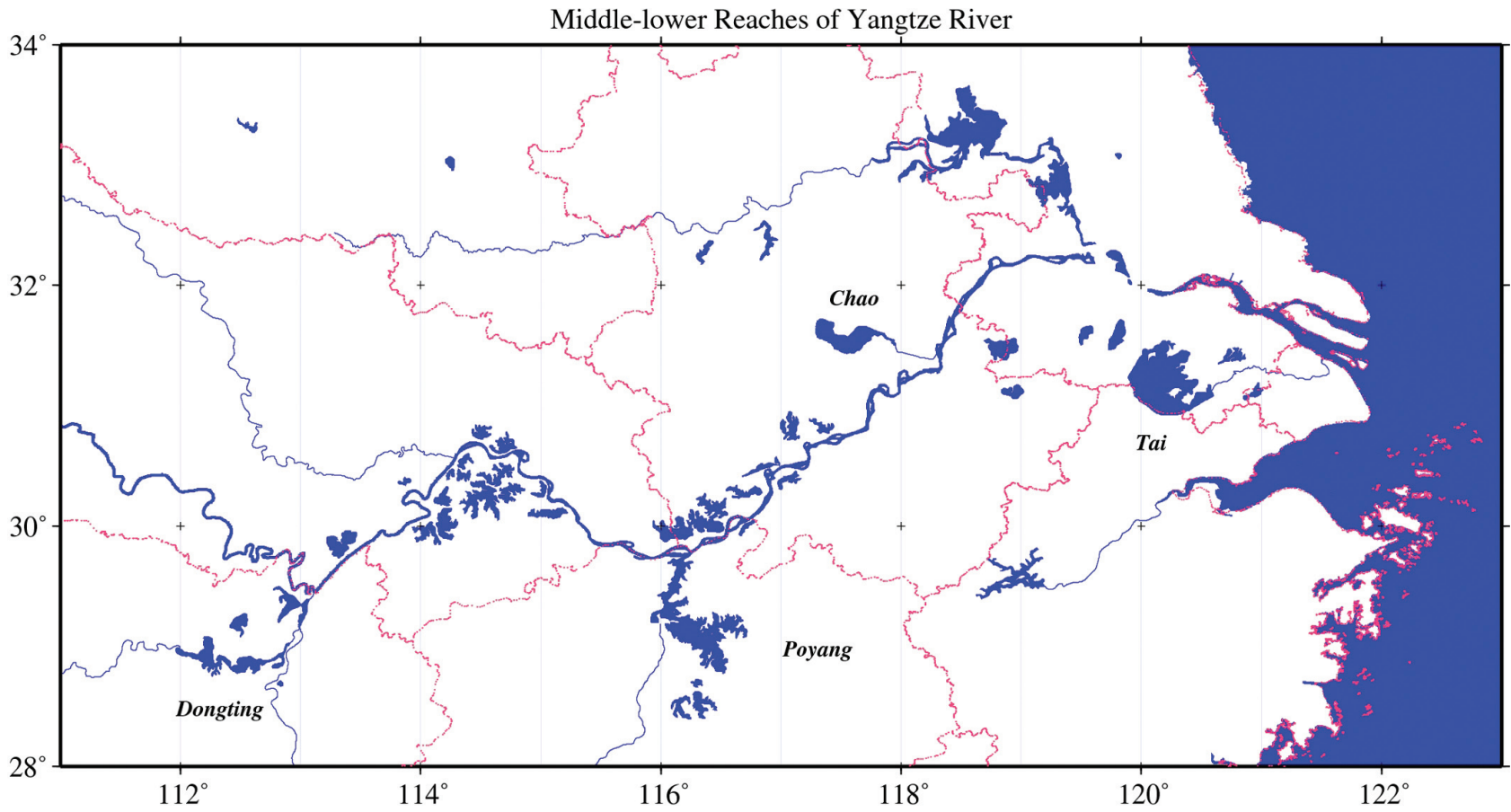

Fig. 1. The middle-lower reaches of Yangtze River and its lakes. 

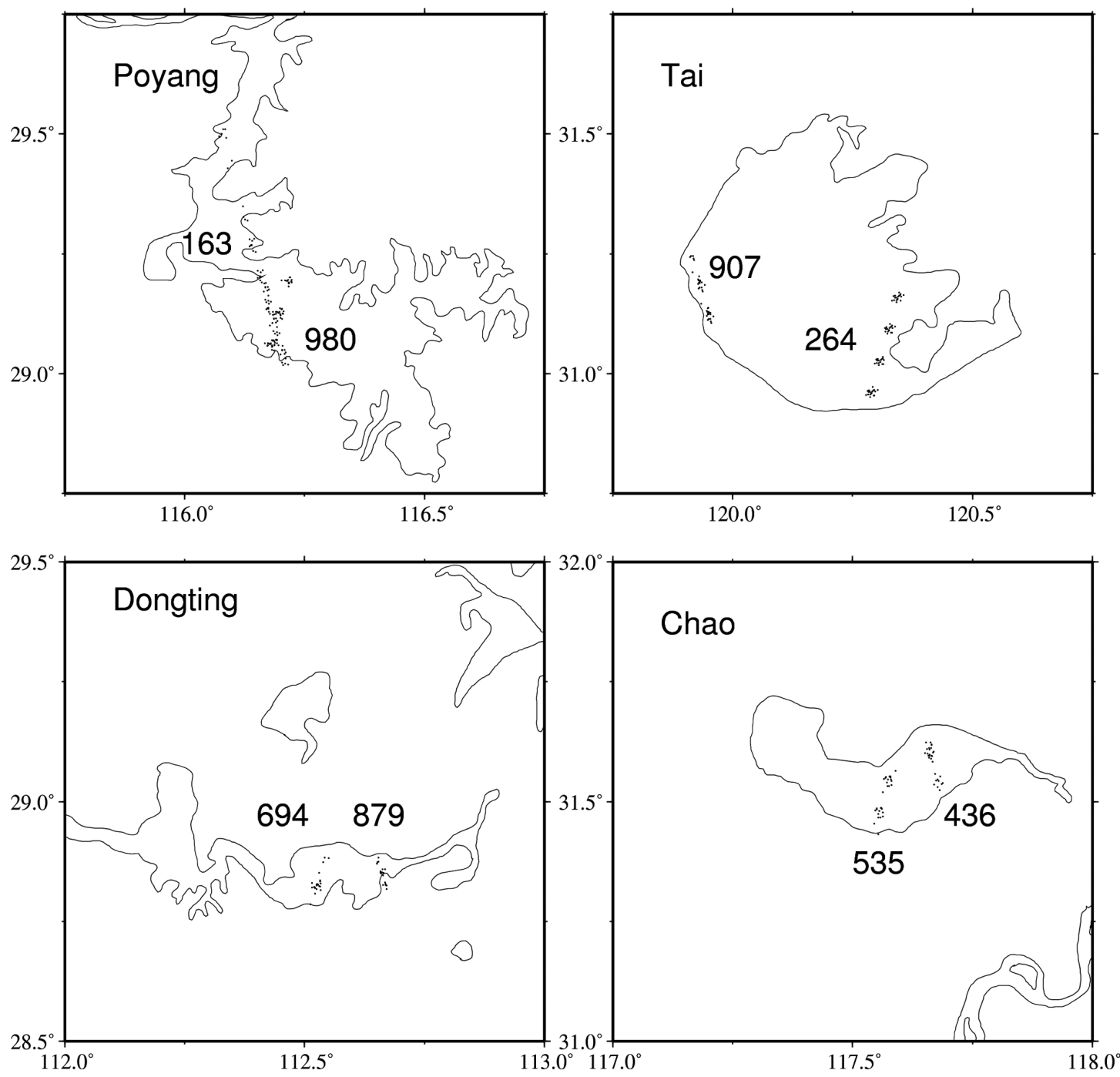

Fig. 2. Geographical locations of the 4 studied lakes and data distribution.

radar altimeter measurement resolution mode, thus avoiding artificial boundaries between geographical features like land/sea, land/ice, or land/lake transitions. This design ensures that ocean, land, ice, lake, or wetland data always ends up in the same (unique, global) data product. Corrections for propagation medium (wet troposphere and ionosphere correction) were not available in the ENVISAT GDRs data used for this study.

In order to capture more data for the analysis, special editing criteria suitable for inland waters were adopted bearing in mind the surface areas of the lakes as well as the sparse altimetric data distribution over the lakes. In our processing, three flags namely a data quality flag, altimeter surface type flag and the number of $18 \mathrm{~Hz}$ valid points for Ku-band ocean range ( $>10)$ were taken into account. Editing by thresholds, as is normally done to data over oceans (ESA 2006; CLS 2003, 2004), was not considered. As advised by ESA (2005), corrections applied to the measured altimeter ranges were troposphere correction (dry and wet), ionosphere correction, solid earth tide, pole tide, and instrument bias. Among these corrections, wet troposphere corrections and ionosphere corrections are replaced by the MWR correction and DORIS corrections, respectively.

Finally, the lake level height $(L L H)$ with respect to the geoid is computed as follows:

$L L H_{i}=R_{a l t}-R_{i}-\Delta R_{i}-N_{i}$

where $L L H_{i}$ is the lake level height with respect to geoid; $R_{a l t}$ is the altitude of altimeter above reference ellipsoid; $R_{i}$ is the $1 \mathrm{~Hz} \mathrm{Ku}$-band range; $\Delta R_{i}$ is the range corrections, including: troposphere correction (model dry correction and MWR wet correction), ionosphere correction, solid earth tide, and pole tide (provided in the ENVISAT GDRs or SGDRs); and $N_{i}$ is the geoid height using EGM96. 
Generally, the mean lake level height $(M L L H)$ are computed based on all level heights although there are several heights along one pass:

$M L L H=\frac{1}{n} \sum_{i}^{n} L L H_{i}$

where $n$ is the total point number of the measured altimetric lake height. Therefore, the level anomaly $\left(L L A_{i}\right)$ is:

$L L A_{i}=L L H_{i}-M L L H$

After obtaining the $L L A_{i}$ corresponding to every level height, the level anomalies per day are averaged. Finally, using the time series of lake level fluctuations, the map of variations were plotted. Generally speaking, it is necessary to use filtering to optimize the levels derived from radar altimetry for high noise level (Hwang et al. 2005).

Unfortunately, the ground-based gauge data is unavailable for the 4 studied lakes. We just use the $1-\mathrm{Hz}$ ocean retracked data provided in the GDRs and no retracking techniques were employed. Table 1 shows some features of the four studied lakes from the ENVISAT data.

\section{ANALYSIS OF LAKE LEVEL VARIATION AND CLIMATE}

\subsection{Poyang Lake}

Poyang Lake is the largest fresh-water lake and the largest natural lake regulating or controlling the Yangtze River. Its rise and fall during flood and non-flood seasons is affected by five rivers (Ganjiang, Fu, Xinjiang, Rao, and Xiu) and the Yangtze River. The major flood period for the aforementioned five rivers is from April to June, at which time the level of Poyang Lake is influenced by water discharged from these five rivers. Nevertheless, the lakes level still remains relatively low. Water volume from these five rivers declines from July to September; however, this is the major annual flood period for the Yangtze River. At this time the lake level steadily rises and remains high coming to a head in July because of reverse water flow. Consequently, flooding disasters at Poyang Lake often occur during the flood period for the Yangtze River.

Two tracks of ENVISAT pass over Poyang Lake. The track 163 is an ascending pass and 980 is a descending pass (Fig. 2 and Table 1). After data editing and processing, 167 measurements were obtained (Table. 1). Column 5 of Table 1 is the mean orthometric height referenced to EGM96 geoid based on point numbers under column 6 of Table 1 from Eq. (2). Monthly variations are computed from Eq. (1) to (3).

Figure 3 shows the seasonal changes of the levels from Oct. 2002 to Dec. 2005. The amplitude of fluctuations amounts to $2.8 \mathrm{~m}$ in July 2003 and $2.0 \mathrm{~m}$ in July 2004 and $2.6 \mathrm{~m}$ in June 2005 , but the amplitude is low and stable in winter and springtime. All show a connection with the level of the Yangtze River. The black points are measuring point level variations derived from radar altimeter measurement. The blue line (circle) shows the monthly variations of the levels and the red line (triangle) is the fluctuations after Gaussian filtering is used with a window of six months (Wessel and Smith 2004; Hwang et al. 2005).

\subsection{Dongting Lake}

Dongting Lake, the second largest lake in China at 17.8 $\times 10^{9}$ stere, is located at the middle reaches of the Yangtze River and stretches across the Hunan and Hubei provincial border. South Dongting is the lake that we studied.

The mean annual temperature is about $16 \sim 17^{\circ} \mathrm{C}$ and the geophysical location is subtropical. There are four riv-

Table 1. The locations and features of the studied lakes (Reference ellipsoid: equatorial radius $=6378.137 \mathrm{~km}$, flattening coefficient $=$ $1 / 298.257223563)$

\begin{tabular}{|c|c|c|c|c|c|c|c|}
\hline Lake & $\begin{array}{c}\text { Borders } \\
\text { Latitude }\left(^{\circ}\right) \\
\text { Longitude }\left({ }^{\circ}\right)\end{array}$ & Province & $\begin{array}{l}\text { Areas } \\
\left(\mathbf{k m}^{2}\right)\end{array}$ & $\begin{array}{c}\text { Mean } \\
\text { Orthometric } \\
\text { height }(\mathbf{m})\end{array}$ & $\begin{array}{c}\text { Point } \\
\text { numbers }\end{array}$ & Pass & Type \\
\hline Poyang & $\begin{array}{c}28.75-29.75 \\
115.75-116.75\end{array}$ & Jiangxi & 3960 & 11.76 & 167 & 163,980 & open \\
\hline Dongting & $\begin{array}{c}28.50-29.50 \\
112.00-113.00\end{array}$ & Hunan & 2740 & 27.59 & 65 & 694,879 & open \\
\hline Tai & $\begin{array}{c}30.75-31.75 \\
119.75-120.75\end{array}$ & Jiangsu & 2425 & 1.00 & 197 & 264,907 & reservoir \\
\hline Chao & $\begin{array}{c}31.25-32.00 \\
117.00-118.00\end{array}$ & Anhui & 780 & 6.10 & 82 & 436,535 & reservoir \\
\hline
\end{tabular}


ers (Xiangjiang, Zi, Yuan, and Li) that flow into Dongting from the south, and four outfalls which link it to the Yangtze River from the north. The lake's water flows into the Yangtze River at Yueyang. Dongting Lake is a naturally big reservoir receiving water from the aforementioned four rivers. It gorges or at times disgorges into the Yangtze River. At the same time, it regulates flooding. The level of the lake is affected not only by rainfall, surface runoff and lake conservation, but also by the situation along the Yangtze River. The advent of the flood season for its four feeding rivers starts in April and causes the level of Dongting to rise (Fig. 4). During the flood season in the Yangtze River's catchment area, from June to September, the level of Dongting Lake rises continuously. Generally speaking, the highest water level appears in July. After September water intake is less than output and the water level in the lake declines slowly before reaching a minimum prior to March of the ensuing year.

\subsection{Tai Lake}

Tai lake, located at mid-latitudes of the northern subtropical zone, is the third largest fresh water lake in China. Interaction between warm-wet airflow coming from the south-east with cold airflow coming from the north causes persistent cloud cover in the region resulting in substantial rainfall during the change from spring to summer every year. These rains known as the Meiyu (plum rains) often cause flooding and disaster. When summer arrives, the weather over Tai Lake is clear and hot because it is controlled by the

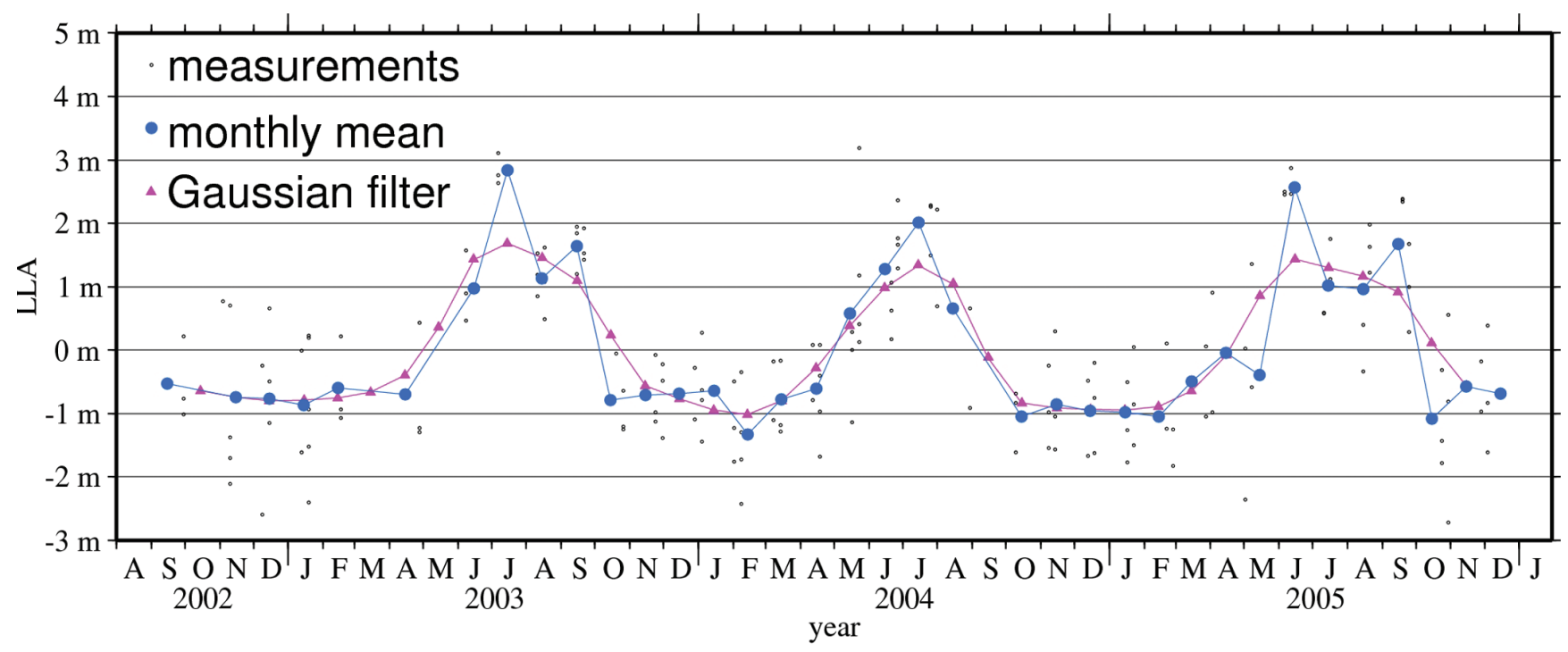

Fig. 3. Monthly mean level variations of Poyang Lake (2002.10 - 2005.12).

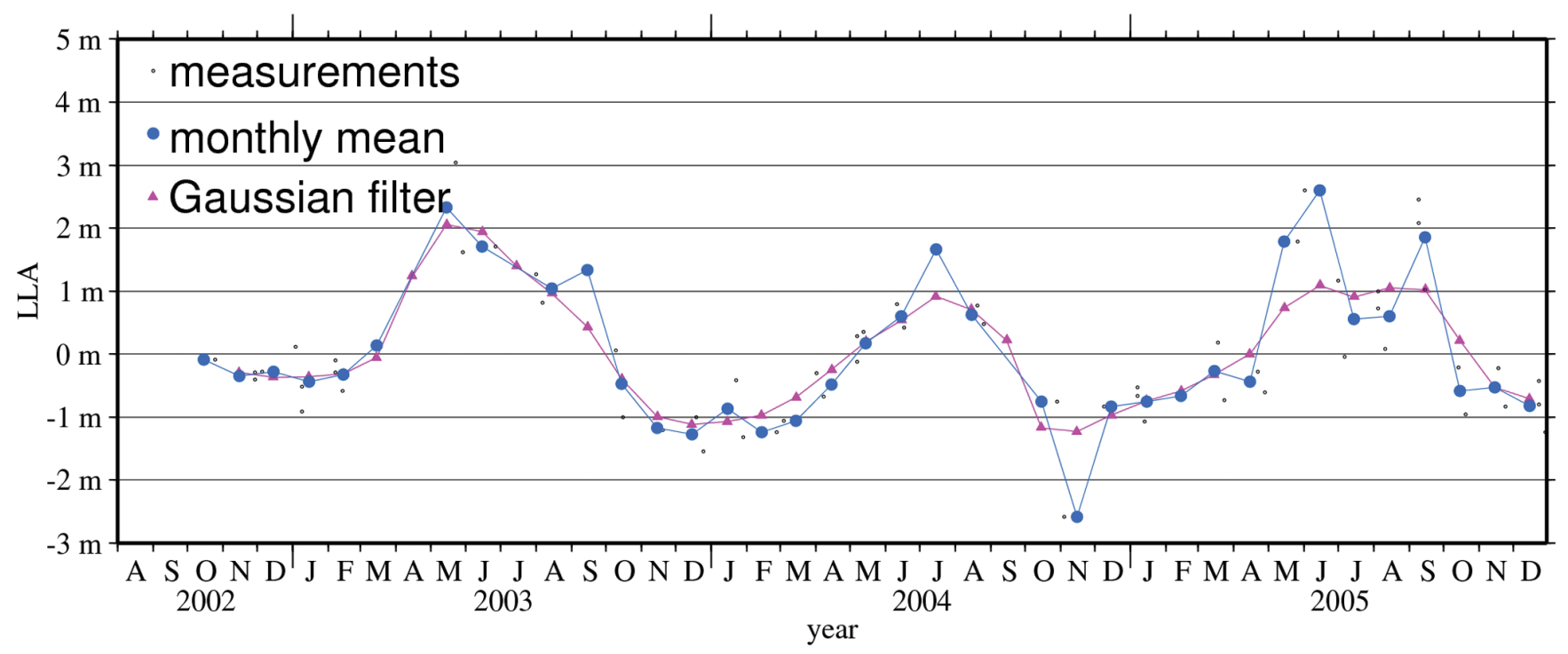

Fig. 4. Monthly mean level variations of South Dongting Lake (2002.10 - 2005.12). 
subtropical high pressure zone. However, tropical storms and typhoons can bring about violent rainstorms during this period. Figure 5 shows the fluctuations of Tai Lake. In general, the level rises in summer and decreases in winter. From Fig. 5, we can see the results derived from ENVISAT showing that the level usually rises in March or April and keep rising from May to September and then decreases after October. A floodgate has been built for Tai Lake to regulate water flow. For this reason, the catchment areas of Tai Lake are usually devoid of flooding even at lower elevations.

\subsection{Chao Lake}

Chao Lake, one of the five largest fresh water lakes in China, is shallow and close to the Yangtze River. There are many foothills in the catchment areas and Yinping, Fenghuang, and Dabieshan mountains line the river basin. A dense network of crisscrossing rivers (Hangbu, Fengle, Pai, Nanfei, Dianbu, and Zhegao Rivers) flow into Chao Lake, and only the Yuxi River, which is linked to Yangtze, flows out from Chao Lake.

In the summer of 2003, the Chao could not be drained due to the draining of the Longhekou reservoir (upper reaches of the Hangbu River) and heavy rain in the upper reaches. The only floodgate of Chao Lake was closed as the level of the Yuxi was higher than that of Chao Lake by the end of June. So the level of Chao Lake kept rising in July and didn't begin declining until August. A comparison of the levels of 2003, 2004, and 2005 derived from ENVISAT is presented in Fig. 6. Generally, the level rises from May

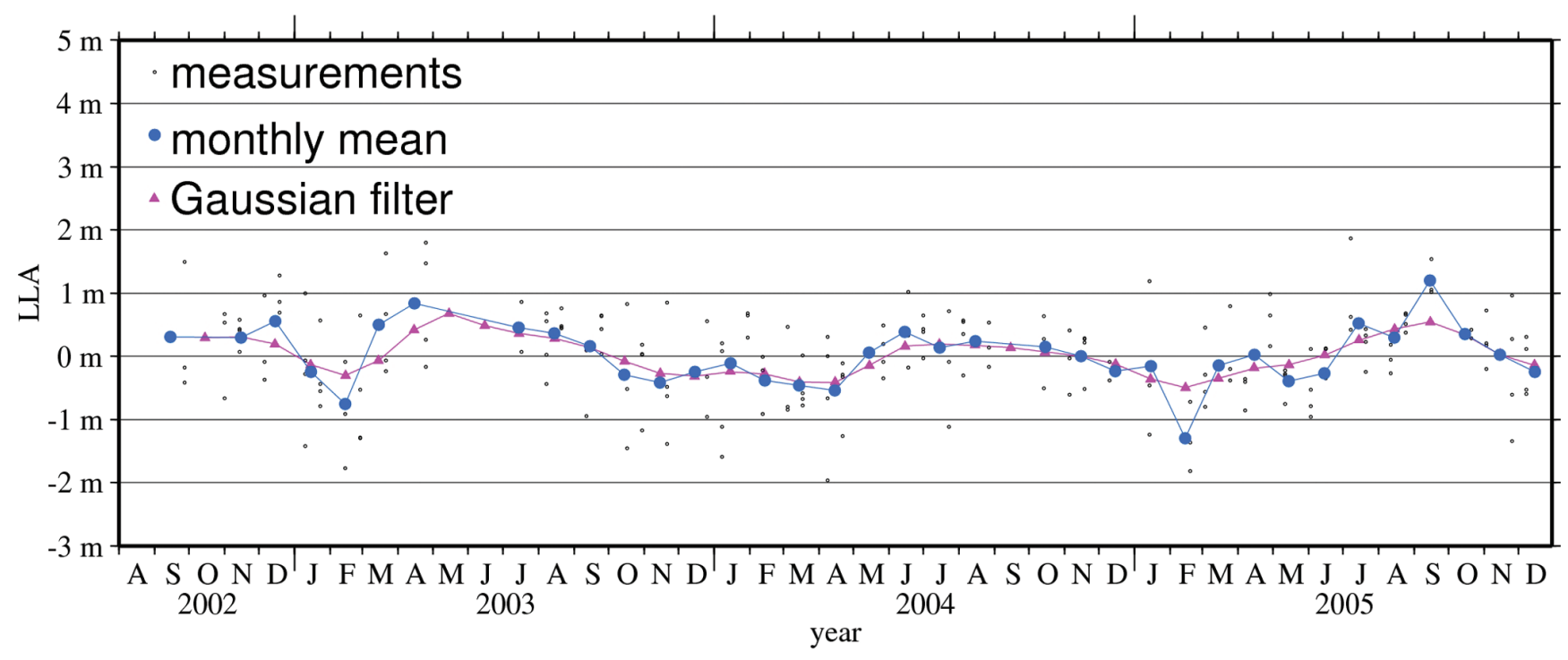

Fig. 5. Monthly mean level variations of Tai Lake (2002.10-2005.12).

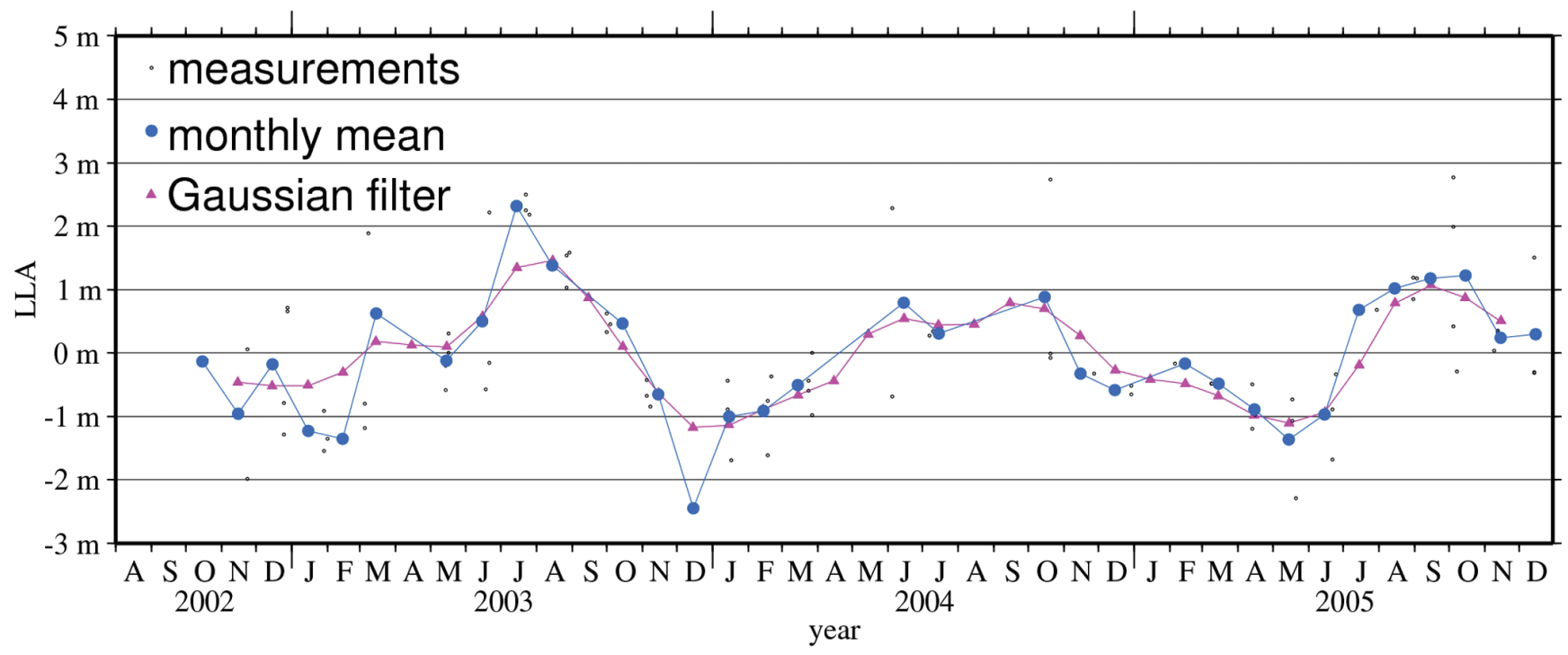

Fig. 6. Monthly mean level variations of Chao Lake (2002.10 - 2005.12). 
and keeps rising with the Meiyu, reaching a peak in July or August, which is the flood season for the Yangtze River. The lowest water level appears in winter in January or February.

\section{CONCLUSION AND OUTLOOK}

Although satellite radar altimeters were initially developed to operate over ocean surfaces and make precise measurements of the sea surface topography, they can also be applied to inland water bodies and become a powerful tool in the study of regional hydrological systems as well as the relationship between water level changes and climate. In this paper, water level time series of Poyang, Dongting, Tai, and Chao Lakes are studied and the correlation between water level and climatic changes within the basin are discussed using 3 years of ENVISAT data based on some simple data editing criteria. The results show that water level changes of the four studied lakes follow a similar trend, not only in rise but also in decline, and that this trend has apparent seasonal features. Fluctuations in water levels at the lakes have a positive correlation with the level of the Yangtze River. In the future, if possible, GFO, ERS1/2, T/P, JASON-1, and ENVISAT data could be used to provide multi-altimetry and long time-series numerical results. Waveform retracking technology could also help improve the accuracy of altimetric range over inland lakes.

Acknowledgements The authors thank their colleagues for continuing support and discussion. The paper benefits from constructive comments and review from Prof. C. K. Shum, Cheinway Hwang, Dr. Calmant, and other anonymous referees. The authors are also grateful to the ENVISAT data provided by ESA. This study is funded by the Natural Science Foundation Committee of China under grants 40474004 and national 863 project of China under grants 2006AA09Z138 and 2006AA12Z309.

\section{REFERENCE}

Birkett, C. M., 1995: The contribution of Topex/Poseidon to the global monitoring of climatically sensitive lakes. $J$. Geophys. Res., 100, 25179- 25204.

Birkett, C. M., 1998: Contribution of TOPEX NASA radar altimeter to global monitoring of large rivers and wetlands. Water Resour. Res., 34, 1223-1239.

Birkett, C. M., R. Murtugudde, and T. Allan, 1999: Indian Ocean climate event brings floods to east Africa's lake and the Sudd Marsh. Geophys. Res. Lett., 26, 1031-1034.

Campos, O., F. Mercier, C. Maheu, G. Cochnneau, P. Kosuth, D. Blitzkow, and A. Cazenave, 2001: Temporal variations of river basin waters from Topex-Poseidon satellite altimetry: Application to the Amazon basin.
Earth Planet. Sci., 333, 633-643.

Chelton, D. B., J. C. Ries, B. J. Haines, L. L. Fu, and P. S. Callahan, 2001: Satellite Altimetry and Earth Science, Academic Press, $131 \mathrm{pp}$.

Chu, Y. H., J. C. Li, W. P. Jiang, and Y. Zhang, 2005: Monitoring the Hulun Lake level and its fluctuation with Jason-1 altimetric data. J. Geodesy Geodyn., 25, 11-16. (in Chinese)

CLS, 2003: ENVISAT RA2/MWR ocean data validation and cross calibration activities, Yearly report 2003, 1, $118 \mathrm{pp}$.

CLS, 2004: ENVISAT RA2/MWR ocean data validation and cross calibration activities, Yearly report 2004, 1, $108 \mathrm{pp}$.

ESA, 2005: ENVISAT RA2/MWR Product Handbook, European Space Agency, 2, 384 pp.

ESA, 2006: ENVISAT RA-2 / MWR Level 2 User Manual, European Space Agency, 1, 150 pp.

Hwang, C., M. F. Peng, J. S. Ning, J. Luo, and C. H. Sui, 2005: Lake level variation in China from TOPEX/POSEIDON altimetry: Data quality assessment and links to rrecipitation and ENSO. Geophys. J. Int., 161, 1-11, doi: 10.1111/j.1365-246X.2005.02518.x.

Jekeli, C., and P. Dumrongchai, 2003: On monitoring a vertical datum with satellite altimetry and water-level gauge data on large lakes. J. Geodesy., 77, 447-453.

Jiang, W. P., 2001: The application of satellite altimetry in geodesy. Ph.D. Thesis, School of Geodesy and Geomatics, Wuhan University, Wuhan, China, 130 pp. (in Chinese)

Mercier, F., A. Cazenave, and C. Maheu, 2002: Interannual lake level fluctuations (1993 - 1999) in Africa from Topex/Poseidon: Connections with ocean-atmosphere interactions over the Indian Ocean. Global Planet. Change, 32,141-163.

Morris, C. S., and S. K. Gill, 1994: Evaluation of the TOPEX/POSEIDON altimeter system over the Great Lakes. J. Geophys. Res., 99, 24527-24539.

Phillips, H. A., 1999: Applications of ERS satellite radar altimetry in the Lambert Glacier-Amery Ice Shelf System, East Antarctica. Ph.D. Thesis, Antarctic CRC and Institute of Antarctic and Southern Ocean Studies, University of Tasmania, Hobart, Australia, 293 pp.

Ponchaut, F., and A. Cazenave, 1998: Continental lake level variations from Topex/Poseidon (1993 - 1996). Comptes Rendus De I'Academie des Sciences Series IIA Earth and Planetary Science, 326, 13-20.

Wessel, P., and W. H. F. Smith, 2004: The Generic Mapping Tools GMT, Version 4, 154 pp.

WOCE/NASA, 1988: World Ocean Circulation Experiment, US WOCE Technical Report Number 2, 76 pp.

Zhang, J. Q., K. Q. Xu, Y. G. Yang, L. H. Qi, S. Hayshi, and M. Watanabe, 2006: Measuring water storage fluctuations in lake, Dongting, China, by Topex/Poseidon 
satellite altimetry. Environ. Monit. Assess., 115, 23-37, doi: 10.1007/s10661-006-5233-9.

Zhang, K., 2002: Monitoring continental lake level varia- tions by using satellite altimeter data. Master Thesis, School of Geodesy and Geomatics, Wuhan University, Wuhan, China, 49 pp. 